\title{
Research on Government Accounting Reform and Innovation from Perspective of Prevention and Control of Government Debt Risks
}

\author{
Zhang Kai \\ Henan University of Animal Husbandry and Economy School of Finance and Accountancy, \\ ZhengZhou, HeNan, China \\ 417675502@qq.com
}

Keywords: Government debt risk, Government accounting reform, Accrual basis

\begin{abstract}
The financial crisis in 2008 caused the global economic recession, and many countries faced government debt problems. Subsequently, Iceland, Greece and other sovereign countries faced "national bankruptcy", and sovereign debt risks spread rapidly. In order to cope with government debt risks, many countries reformed government accounting. The economic crisis has also exerted a huge impact on China. In order to cope with this, the government has taken measures such as increasing government investment, but it has brought about a series of problems such as the sharp increase of local government debt. The intensification of government debt risk has promoted the government accounting reform in China. This paper studies the current situation of government accounting reform under the prevention and control of government debt risk, the existing problems at the present stage, and the causes of the problems, and then puts forward the opinions and Suggestions on the reform and innovation of government accounting.
\end{abstract}

\section{政府性债务风险防控视角下的政府会计改革与创新研究}

\author{
张铠 \\ 河南牧业经济学院金融与会计学院，郑州，河南，中国 \\ 417675502@qq.com
}

关键词：政府性债务风险; 政府会计改革; 权责发生制

中文摘要: 2008年的金融危机引起了全世界经济的衰退, 许多国家面临政府债务问题, 随后冰 岛、希腊等主权国家面临“国家破产”，主权债务风险迅速蔓延，为了应对政府性债务风险许 多国家对政府会计进行改革。经济危机对我国也产生了巨大影响，为了应对我国政府采取了 加大政府投资等措施，但随之带来了地方政府债务剧增等一系列问题，政府性债务风险的加 剧促进了我国政府会计改革。本文通过对政府性债务风险防控下的政府会计改革现状、现阶 段存在的问题、问题产生的原因进行研究，进而提出政府会计改革与创新的意见与建议。

\section{1. 引言}

上世纪70年代末，由于西方国家政府采取扩张的财政政策引起了严重的财政赤字，政府 负债剧增, 面临巨大的偿债压力。在这样的压力下, 西方许多国家痛定思痛, 发起了“新公共 管理运动”，新公共管理运动的核心为政府再造，强调对政府进行企业化管理，将成本核算、 绩效评估等引入政府管理, 目的是提提升政府工作效率, 这是政府会计改革的起点。进入 21 世纪，受经济危机的影响，各国政府性债务剧增，政府面临的财政压力不断增加，2009年以 来许多国家遭受了严重的政府性债务危机，诸如希腊、冰岛等国甚至面临“国家破产”，这迫 
使众多国家开始思考如何对政府会计进行改革。我们国家也面临西方国家同样的问题和压力, 为了应对经济危机, 我国政府加大了政府投资, 进而带来了地方政府债务剧增, 虽然造成这 些后果的原因是政府行为失当，但是政府会计没有发挥“政府经济警报器”的作用，并没有起 到事先预警的作用，因此可见政府会计存在许多问题，因而迫切需要对政府会计进行改革与 创新。

\section{2. 国内外文献综述}

\section{1国外研究文献回顾}

国外对政府性债务问题的研究比较早，主要集中在对债务风险的监控与方法，制定预警 机制, 并对其进行实时监控。1930年最初以亚当·斯密和李嘉图为代表的的学者持“债务有害 论”观点, 由于 30 年代出现的大衰退, 梅纳德.凯恩斯等学者重新思考提出了“政府债务新理 论”。90年代初, 学者们又将政府债务风险控制做为研究的重点, Hana Polackova Brixi(1988) 提出了“财政风险矩阵”, 明确了政府债务的分类标准, 使各国政府开始对隐性与或有债务进 行了关注。在研究政府负债的同时，一些学者开始关注政府会计在政府负债风险控制中的作 用。Evans and Datton(1987)发现政府债务水平与政府会计信息披露质量存在显著的正相关关 系。Thomas· D. lynch(2002) 认为政府对于政府债务风险衡量具有非常重要的作用。Allen Schick(2003)提出通过政府会计能够及时识别和提供政府债务信息，认为政府会计对于有效控 制政府负债风险具有重大作用。

\section{2国内研究文献回顾}

国内学者的研究主要集中在以下三个方面: 第一，政府债务管理受政府会计不足的影响。 邢俊英（2004）认为在预防财政负债风险方面财政总预算会计制度存在不足。王金秀、柳宇 燕（2011）汇总了现行预算会计对财政风险管理产生的负面影响。杨亚军（2013）通过对欧 洲各国的债务危机分析得出导致债务危机扩散的主要原因之一是政府会计没有为政府防范财 政风险提供预先的警告。第二，政府会计改革要为债务风险控制服务。江秀英（2014）提出 政府会计改革的目标是为政府控制负债风险及时提供有用的信息，达到预警作用。第三，政 府会计的权责发生制改革。邢俊英（2006）提出现阶段的收付实现制难以完全反映政府资产 和负债的情况，许多隐性债务和或有负债被忽视，政府会计难以发挥应用的作用。赵利明 （2012）提出“双计量基础”，提出将权责发生制引入政府会计核算中来。

\section{3研究评述}

国内外学者通过研究发现现行收付实现制下的政府会计，不能够完全反映政府的资产和 负债情况, 特别是对于隐性债务容易被隐藏。许多学者对政府性债务风险和政府会计改革都 有研究，但是绝大多数仅就政府会计对政府债务的预警、收付实现制与权责发生制对政府会 计的影响、以及政府会计在负债等信息披露中的某一个方面进行了研究。本文通过对政府性 债务风险防控下的政府会计的现状进行分析，发现存在的问题，问题产生的原因并有针对性 地提出政府会计改革的对策意见，可以更好的预付政府性债务风险。

\section{3. 我国政府性债务风险现状}

为了掌握我国政府性债务的规模及层级，2013年9月审计署组织全国审计机关对中央、31 个省、396个市、2778个县、33091个乡的政府性债务情况进行了全面审计。

\section{1我国政府性债务的规模及层级}

通过《全国政府性债务审计结果》汇总得出见表1,2012年年底政府负有偿还责任债务共 计190658.59亿元，其中中央94376.72亿元，地方96281.87亿元，中央与地方相差不大。政府 
负有担保责任债务共计 27707 亿元, 其中中央 2835.71 亿元, 地方 24871.29 亿元, 地方占比达 $89.77 \%$ 。政府可能承担一定救助责任债务共计 59326.32亿元, 总规模较大, 其中中央 21621.16 亿元, 地方 37705.16 亿元, 地方仍然占比超过中央。至2013年6月, 政府负有偿还责任债务 206988.65 亿元, 比上年增长了 $8.57 \%$ 。政府负有担保责任债务 29256.49 亿元, 比上年增长了 $5.59 \%$ 。政府可能承担一定救助责任债务66504.56亿元，比上年增长了 $12.10 \%$ 。

表1 全国政府性债务规模

单位: 亿元

\begin{tabular}{ccccc}
\hline 年度 & 层级 & 政府负有偿还责任债务 & 政府负有担保责任债务 & 政府可能承担一定救助责任债务 \\
\hline 2012年底 & 中央 & 94376.72 & 2835.71 & 21621.16 \\
& 地方 & 96281.87 & 24871.29 & 37705.16 \\
& 总计 & 190658.59 & 27707.00 & 59326.32 \\
2013 年6月 & 中央 & 98129.48 & 2600.72 & 23110.84 \\
& 地方 & 108859.17 & 26655.77 & 43393.72 \\
& 总计 & 206988.65 & 29256.49 & 66504.56 \\
\hline
\end{tabular}

2013年6月，在全国政府债务中，其中地方政府债务共计178908.66亿元，见表2，其中负 有偿还责任债务的占比最高，共计 108859.17 亿元，占地方政府债务的 $60.85 \%$ 。从表2中我们 还可以看出地方各级政府债务中市级层面占比最高, 达到 $40.75 \%$, 这主要是因为我国采用分 税制, 市级财政税收收入难以满足发展的需要, 市级政府为了发展, 为了取得政绩, 就会大 量举借外债，因而才会出现大量的地方性政府债务。

表2２013年6月底地方各级政府性债务规模及层级结构＼cjkstart单位：亿元

\begin{tabular}{ccccccc}
\hline 层级 & $\begin{array}{c}\text { 政府负有偿还 } \\
\text { 责任的债务 }\end{array}$ & $\begin{array}{c}\text { 政府负有担保 } \\
\text { 责任债务 }\end{array}$ & $\begin{array}{c}\text { 政府可能承担一 } \\
\text { 定救助责任债务 }\end{array}$ & $\begin{array}{c}\text { 地方政府债 } \\
\text { 务总规模 }\end{array}$ & 占比 & $\begin{array}{c}\text { 负有偿还责任 } \\
\text { 债务的占比 }\end{array}$ \\
\hline 乡镇 & 3070.12 & 116.02 & 461.15 & 3647.29 & $2.04 \%$ & $84.18 \%$ \\
县级 & 39573.60 & 3488.04 & 7357.54 & 50419.18 & $28.18 \%$ & $78.49 \%$ \\
市级 & 48434.61 & 7424.13 & 17043.70 & 72902.44 & $40.75 \%$ & $66.44 \%$ \\
省级 & 17780.84 & 15627.58 & 18531.33 & 51939.75 & $29.03 \%$ & $34.23 \%$ \\
合计 & 108859.17 & 26655.77 & 43393.72 & 178908.66 & $100 \%$ & $60.85 \%$ \\
\hline
\end{tabular}

从图1看出, 自2012年至2013年, 全国政府性债务不断上升, 其中政府可能承担一定救助 责任债务上升最快, 政府债务的不断增加, 势必会对未来经济产生不良影响, 因此迫切需要 采取措施来预防和控制政府性债务风险。

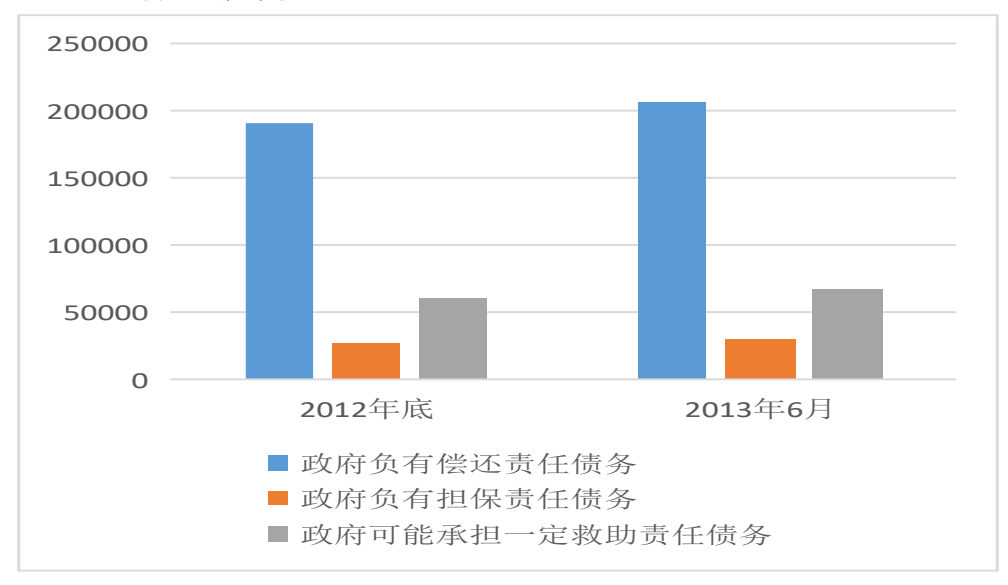

图1：全国性政府债务统计 


\section{2举借主体方面}

截至2013年6月底地方政府性债务举借主体主要是融资平台公司、政府部门和机构、经费 补助事业单位以及其他事业单位等。而其中主要的举债主体又主要是融资平台公司以及政府 部门和机构。我国在应对 2008 年金融危机出台“4万亿政府投资计划”，各地为了这一投资计划 纷纷成立融资平台公司, 用于满足政府投资计划资金需求。然而, 这一融资平台公司的过渡 增长也加重了政府性债务风险。

为了应对2008年金融危机，我国出台了“4万亿政府投资计划”，各地政府资金需求不断提 高, 这促使了各地迅速出现了众多的融资平台公司, 由表3可以看出, 地方政府举借的主体最 主要的是融资平台公司, 在全部举借主体中占比高达 $38.96 \%$, 融资平台公司的爆发性增长迅 速加重了政府性债务风险。其次是政府部门和机构, 占比 $22.69 \%$, 第三是国有独资或控股企 业，第四是经费补助事业单位。这四大举借主体占据地方政府债务的 $92.57 \%$ 。

表3 2013年6月底地方政府性债务举借主体情况

单位: 亿元

\begin{tabular}{cccccc}
\hline 举债主体 & $\begin{array}{c}\text { 政府负有偿还 } \\
\text { 责任的债务 }\end{array}$ & $\begin{array}{c}\text { 政府负有担 } \\
\text { 保责任债务 }\end{array}$ & $\begin{array}{c}\text { 政府可能承担一 } \\
\text { 定救助责任债务 }\end{array}$ & 合计 & 占比 \\
\hline 融资平台公司 & 40755.54 & 8832.51 & 20116.37 & 69704.42 & $38.96 \%$ \\
政府部门和机构 & 30913.38 & 9684.20 & 0 & 40597.58 & $22.69 \%$ \\
国有独资或控股企业 & 11562.54 & 5754.14 & 14039.26 & 31355.94 & $17.53 \%$ \\
经费补助事业单位 & 17761.87 & 1031.71 & 5157.10 & 23950.68 & $13.39 \%$ \\
自收自支事业单位 & 3462.91 & 377.92 & 2184.63 & 6025.46 & $3.37 \%$ \\
其他单位 & 3162.64 & 831.42 & 0 & 3994.06 & $2.23 \%$ \\
公用事业单位 & 1240.29 & 143.87 & 1896.36 & 3280.52 & $1.83 \%$ \\
合计 & 108859.17 & 26655.77 & 43393.72 & 178908.66 & $100 \%$ \\
\hline
\end{tabular}

\section{3地方政府性债务余额未来偿还方面}

由表4看出，从2014-2016年和2018年政府债务水平都处于较高的水平，因而政府将会面 临巨大的偿债压力, 这必然会影响经济和社会的可持续发展, 因而如何有效地避免政府性债 务风险是迫切需要解决的问题。

表4２013年6月底地方政府性债务余额未来偿债情况表 单位: 亿元

\begin{tabular}{cccc}
\hline 偿债年度 & $\begin{array}{c}\text { 政府负有偿还责任 } \\
\text { 的债务 }\end{array}$ & $\begin{array}{c}\text { 政府负有担保责任 } \\
\text { 债务 }\end{array}$ & $\begin{array}{c}\text { 政府可能承担一定 } \\
\text { 救助责任债务 }\end{array}$ \\
\hline 2014 年 & 23826.39 & 7481.69 & 4373.05 \\
2015 年 & 18577.91 & 5994.78 & 3198.42 \\
2016 年 & 12608.53 & 4206.51 & 2606.26 \\
2017 年 & 8477.55 & 3519.02 & 2298.6 \\
2018 年及以后 & 20419.73 & 16669.05 & 11706.75 \\
合计 & 83910.11 & 37871.05 & 24183.08 \\
\hline
\end{tabular}

综合上述分析，可以看出，目前我国政府性债务存在诸多问题，第一，债务规模较大， 特别是隐性债务规模占比也比较大; 第二, 债务增长速度较快, 从1998-2010年地方政府债务 规模平均增长速度为 $33.87 \%$; 第三, 债务关系复杂, 由于地方政府融资平台的存在, 造成复 杂的债务关系。而造成上述问题的主要原因是由于我国目前还没有建立完善的政府财政资金 管理体系, 而现阶段我国的政府会计体系不能有效地对政府性债务风险进行防范和预警, 因 此需要加快对我国政府会计的改革，通过政府会计来有效预防政府性债务风险。 
4. 我国政府会计现状及存在的问题

\section{1政府性债务会计信息披露不完善}

现阶段我国政府会计体系并没有完善的政府信息披露制度，虽然财政预算报告能够反映 当期的预算收入和支出情况，但是对于隐性债务、或有负债、表外负债等众多债务信息并不 能有效地披露, 很难全面有效的反映政府的财务情况。而且政府会计没有对地方政府的负债 以及成本费用等情况进行披露, 造成政府会计并不能对政府性债务风险进行有效的预防和预 警。

\section{2政府会计法规与制度建设落后}

我国政府会计体系还不够完善，不能满足当前政府性债务风险的有效防控。在《预算法》 和《会计法》中却很少有关于政府会计的相关条款，未对政府会计做出相关的规定。然而， 要实现政府财政财务管理水平的有效提升, 就必须法规先行, 只有在有法可依的条件下, 政 府会计改革的事业才能更好的进行。

目前我们国家的政府会计体系还不够成熟，虽然国家制定了《预算法》和《会计法》， 但其中对于政府会计的相关内容少之又少, 并没有明确的对政府会计做出规定。而政府性债 务风险的存在促使政府会计做出变革, 因此就需要国家出台配套的法律法规, 对政府会计做 出明确的规定，政府会计改革才能有序进行。

\section{3政府性债务会计信息缺乏严格的内外部监管}

前面我们分析由于政府会计信息对于隐性债务以及或有负债不能有效的披露，导致政府 会计不能发挥应有的防控作用，导致政府性债务风险迅速扩张。但是由于对于政府性债务会 计信息缺乏有效的内外监督和管理，造成政府性债务风险的危害又进一步加深。目前我国的 政府审计对于政府性债务会计信息缺乏连续性和可持续性审计，造成政府性债务风险不断膨 胀，因此政府审计在政府性债务风险监督中的缺失，进一步加大了政府性债务风险。

\section{4政府会计改革配套机制不健全}

人才和信息技术对于政府性债务风险防控下的政府会计改革非常重要。而我国政府部门 的会计从业人员由于长期采用收付实现制进行会计核算, 需要加大对人员的培训。同时，随 着大数据时代的到来, 需要各单位改进政府性债务会计信息的处理技术, 建立相应的数据库, 为政府性债务风险防控下的政府会计改革提供良好的基础。

\section{5.政府性债务风险防控下的政府会计改革建议}

\section{1改进政府会计信息披露制度}

政府作为公共受托责任人，有责任和义务向公众报告受托责任履行情况，但是预算会计 体系下，政府会计报告只反映了预算的收支情况，对于政府性债务公众很难通过报告了解， 因此各级政府应当在政府单位网站上对政府性债务信息进行有效的披露，使公众能够清楚的 了解政府的债务情况。此外, 通过对政府财务会计信息和预算会计信息进行同时披露的形式, 一方面既可以反映政府预算收支情况，另一方面又可以满足公众以及政府审计部门对政府性 债务信息的需求，可以有效的预防政府性债务风险。

\section{2完善预算会计以促进政府会计改革}

由于我国政府职能发生了变化，政府活动日趋丰富，单一的政府预算会计体制很难适应 新的发展, 因此需要对政府会计进行改革。受金融危机的影响, 我国采用了扩张性的财政政 策，地方政府融资平台的迅速扩张造成了政府性债务风险剧增而我国之前的预算会计对于政 府的隐性债务和或有负债很难全面反映, 又进一步加剧了政府性债务风险, 因此需要尽快完 
善预算会计，通过修订新预算法实施条例和规章制度，发挥政府预算会计在政府预算体制中 的作用，协调新预算法下的预算会计和财务会计，并通过政府财务会计体系有效防控政府会 计风险。虽然国家已经发布了新预算法, 将政府性债务纳入预算管理, 但是想要有效预防政 府性债务风险, 还需要进一步建立完善的政府会计法律法规, 确定政府工作中的相关原则和 方法, 使得政府会计工作有法可依。此外进一步建立完善的政府会计准则体系, 使政府会计 工作有章可循。

\section{3强化国家审计与社会公众对政府会计信息的监督}

国家审计具有监督政府权力、政府绩效，维护国家经济安全的重要作用，国家审计通过 对政府的资产负债情况，尤其是隐性债务和或有负债进行审计，可以发现政府在财政资金使 用过程中存在的问题，对政府财政存在的潜在风险进行预防。同时国家审计出具的政府性债 务风险审计报告还可以促使政府会计建立政府性债务风险预警机制。

此外，社会公众作为纳税人也需要强化自身的主人翁意识，积极了解政府有关财政资金 的使用情况, 对政府活动进行监督。同时政府部门为了方便社会公众了解政府财务信息, 需 要创造各种便捷的方式比如在网站披露财务信息、建立信访制度等方式使社会公众能够方便 快捷地了解政府财务情况，进而达到监督的作用，可以有效地避免政府性债务风险。

\section{4健全政府会计改革配套体制机制}

为了顺应政府会计改革，要健全配套机制体制，一方面，要强化对政府工作人员的培训, 既要对会计、审计等专业业务知识进行培训, 而且要加强对计算机信息技术等综合知识的培 训, 通过提升政府会计人员的业务素质，可以提高政府会计人员对于风险的防控意识，进而 达到预防政府性债务风险的目的。另一方面, 要不断提升我国政府性债务会计信息处理的质 量及效率，通过建设全国和地方各级政府的政府性债务信息数据库和信息发布平台等，逐步 实现政府性债务信息的透明和共享，更好地对政府性债务风险进行预警。

\section{致谢}

本文为2019年度河南省软科学研究计划项目《政府性债务风险防控视角下的政府会计改 革与创新研究》（编号：192400410354）、基金项目河南牧业经济学院科研创新团队建设计 划项目（编号：2018KYTD03）的阶段性成果之一。

\section{References}

[1] A Goddard. Accounting and NPM in UK Local Government-Contributions Towards Governance and Accountability. Financial Accountability and Management,2005,21(2):191-218.

[2] Algie, R, 2003. Governance Traditions and Narratives of Public Sector Reform in Contemporary France. Public Administration,81(1):141-162

[3] Athukorala, S.L., and Reid, B. ,2003. Accrual Budgeting and Accounting in Government.

[4] T M Carlin, Debating the Impact of Accrual Accounting and Reporting in The Public Sector. Financial Accountability and Management,2005,21(3):309-333

[5] International Monetary Fund. 2001. Manual on Fiscal Transparency. Washingtong.

[6] Chan. James L.2001 Government Accounting Seminar. Tsinghua University.

[7] Slephen. 2005. Governmental Accounting, Auditing, and Financial Reporting. Government Finance Officers Association. 
[8] Hana Polackova Brixi and Allen Schick. 2002. Government at Risk-Contingent Liabilities and Fisca Risk. Washington: World Bank.

[9] R.J. Freeman, C.D. Shoulders. 1993. Governmental and Nonprofit Accounting: Theory and Practice, Prentice Hall, Inc. 